\title{
Effect provided by dispersed phase on the morphology and properties of composite zinc coatings
}

\author{
R.E. Fomina, G.G. Mingazova, S.V. Vodopyanova* ${ }^{*}$, and R.S. Sayfullin \\ Department of Inorganic Substances and Materials Engineering, Faculty of Chemical Technologies, \\ Institute of Oil, Chemistry \& Nanotechnology, Kazan National Research Technological University, \\ Kazan, Republic of Tatarstan, Russia.
}

\begin{abstract}
We studied the composition of electrochemical titanium and silicon zinc dioxide coatings, as well as the special aspects of their morphology and corrosion resistance. It is found that the particles of $\mathrm{TiO}_{2}$ are included into the zinc matrix. Share of dispersed phase in CEC grows with increasing the concentration of particles in the suspended electrolyte. It is shown that the $\mathrm{SiO}_{2}$ particles are not included into the coating, inhibiting the process of cathodic reduction of zinc. It is also found that crystals on all the coatings obtained have a hexagonal structure, while introducing the dispersed phase particles leads to the plating structure refinement. It is shown that including the $\mathrm{TiO}_{2}$ particles leads to forming the coatings of better corrosion resistance.
\end{abstract}

\section{Introduction}

Developing composite electrochemical coatings (CEC) is one of the key areas in the modern electroplating.

Principle of obtaining CECs is based on coprecipitating dispersed particles of different size together with metals from suspended electrolytes. Being included into coatings, the dispersed phase enhances their performance, such as hardness, durability, and corrosion resistance, and give them new properties, such as antifriction, magnetism, or catalytic properties. Thereby, CECs are extensively used in mechanical engineering, tool engineering, and manufacturing medical appliances [1].

Refractory borides, carbides, nitrides, and silicides; graphite and carbonaceous materials; abrasive powders, lubricants, and oxides are used as second-phase particles [5].

$\mathrm{TiO}_{2}$ particles are known to be used in enhancing the micro hardness and corrosion resistance of nickel-matrix coatings [2], and the $\mathrm{TiO}_{2}$ particles are also a component of the $\mathrm{Zn} / \mathrm{TiO}_{2}$ catalyst of steam methane reforming [3]. However, obtaining zinc-matrix CECs in presence of the $\mathrm{TiO}_{2}$ particles is still poorly known. Zinc coatings with the dispersed phase of $\mathrm{SiO}_{2}$ have better adhesion to the base than pure zinc coatings [4].

This paper studies how titanium and silicon dioxides affect developing zinc-matrix composite electrochemical coatings.

\footnotetext{
* Corresponding author: vod-sveta@yandex.ru
} 


\section{Experiment}

For our study, we used the following composition of the zinc plating sulfate electrolyte, $\mathrm{g} / \mathrm{dm}^{3}: \mathrm{ZnSO}_{4} \cdot 7 \mathrm{H}_{2} \mathrm{O}-300 ; \mathrm{Na}_{2} \mathrm{SO}_{4} \cdot 10 \mathrm{H}_{2} \mathrm{O}-80$; and $\mathrm{Al}_{2}\left(\mathrm{SO}_{4}\right)_{3} \cdot 18 \mathrm{H}_{2} \mathrm{O}-40$. Conditions of obtaining CEC from this electrolyte: $\mathrm{i}_{\mathrm{k}}=5 \mathrm{~A} / \mathrm{dm}^{2} ; \mathrm{pH}=3-4$; and $\mathrm{t}=20 \pm 2^{\circ} \mathrm{C}$. DF concentration in the electrolyte was within the range of $3-50 \mathrm{~g} / \mathrm{dm}^{3}$. Microparticles of titanium dioxide and aerosil were used as the dispersed-phase particles. Thickness of coatings to be formed was $20 \mu \mathrm{m}$. Copper and steel samples were used as cathodes, and zinc plates were used as anodes. $\mathrm{pH}$ of suspensions and of the electrolyte was measured using $\mathrm{pH}-150 \mathrm{M}$, till the stabilization of indication about 4 minutes. Viscosity of suspended electrolytes was measured according to the Russian national standard, GOST 33-2000, using capillary glass viscometer VPZh-2. Zinc current yield was measured coulometrically. Number of the dispersed phase inclusions in coatings was measured by direct and indirect methods.

Phase compositions of coatings were identified using the Rigaku SmartLab diffractometer. Survey parameters: Angular spacing $2 \theta$ from $10^{\circ}$ to $65^{\circ}$ with the fixed tube at $3^{\circ}$ and a sampling interval of 0.02 ; with the point exposure of 1 second.

Morphology of the coating surfaces was identified using the universal industrial microscope Nikon Eclipse LV 100DA-U.

CEC topography and elemental composition were studied by the method of scanning electron microscope investigation and Auger electron microscopy using the micro-sampling device JAMP $9500 \mathrm{~F}$ (JEOL). Studies were performed in the following conditions: Temperature (in laboratory) $-23^{\circ} \mathrm{C}$, humidity (in laboratory) - $34 \%$, primary accelerating voltage $10 \mathrm{kV}$, primary electron beam current $-\approx 0.5 \times 10^{9} \mathrm{~A}$, spatial resolution (electron beam diameter) - at worst $0.03 \mu \mathrm{m}$, and pressure in the analytical chamber - at worst $1 \times 10^{9}$ $\mathrm{mmHg}$ (ultrahigh vacuum).

Polarization curves were read, starting from the stationary values of potentials, in potentiodynamic mode using the potentiostat-galvanostat device IPC-2000, at the potential sweep rate of $1.10 \mathrm{mV} / \mathrm{s}$. Measurements were performed in the three-electrode pressing electrochemical cell YaSE-1. Copper plate of $2 \mathrm{dm}^{2}$ in area was used as the working electrode, chloride silver with the potential of $240 \mathrm{MV}$ was used as the reference electrode $\mathrm{mV}$, and a platinum plate of $3 \mathrm{~cm}^{2}$ in area was used as the auxiliary electrode. Polarization curves of zinc electroreduction in presence of the second phase were read on the as-plated zinc, thickness being $\delta=2 \mu \mathrm{m}$. The findings were displayed on a computer and processed using MS Excel CEC corrosion resistance was identified in accordance with GOST 9.90885 , by changes in the masses of coatings by the method of $3 \%-\mathrm{NaCl}$ solution dipping.

\section{Experimental results and discussions}

We studied the effects provided by the particles of $\mathrm{TiO}_{2}$ and $\mathrm{SiO}_{2}$ on the physical and chemical properties of suspended electrolytes, such as $\mathrm{pH}$ and kinematic viscosity of

Table 1. Dependence of kinematic viscosity on the concentration of $\mathrm{SiO}_{2}$ particles.

\begin{tabular}{|c|c|c|}
\hline $\begin{array}{c}\text { Particles concentration in } \\
\text { suspended electrolyte, } \\
\mathrm{g} / \mathrm{dm}^{3}\end{array}$ & Mean flow time, $\mathrm{s}$ & $\begin{array}{c}\text { Kinematic viscosity, } \\
\mathrm{cm} / \mathrm{s}\end{array}$ \\
\hline 0 & 26.4 & 2.36 \\
\hline 5 & 26.8 & 2.67 \\
\hline 15 & 27.9 & 2.78 \\
\hline 25 & 30.2 & 3.01 \\
\hline
\end{tabular}


electrolytes. Findings show that the particles do not change the $\mathrm{pH}$ of deionized water or zincing electrolyte. Kinematic viscosity of suspended electrolytes grows with increasing the concentration of dispersed-phase particles from 5 to $25 \mathrm{~g} / \mathrm{l}$. High suspension viscosity is determined by forming a 3D-lattice colloidal structure consisting of the $\mathrm{SiO}_{2}$ agglomerates resulting from fixing silanol groups $(=\mathrm{Si}-\mathrm{OH})$ by hydrogen bonds [6].

It is reported in literature [7] that the current yield of acid zincing electrolytes makes 95$100 \%$. In our case, when obtaining coatings from a pure zincing electrolyte, the zinc current yield is $98.4 \%$. For this current yield $(98.4 \%)$, high-quality zinc coatings were obtained at $5 \mathrm{~A} / \mathrm{dm}^{2}$.

From Fig. 1, you can see that particles decrease the zinc current yield with the growth of the concentration of particles. With the $\mathrm{TiO}_{2}$ particles, the zinc current yield decreases by $8.8 \%$, while it decreases by $10.4 \%$ with the particles of $\mathrm{SiO}_{2}$. It can be suggested that dispersed phase inhibits the electroreduction of zinc due to increasing the viscosity of suspended electrolytes (Table 1).

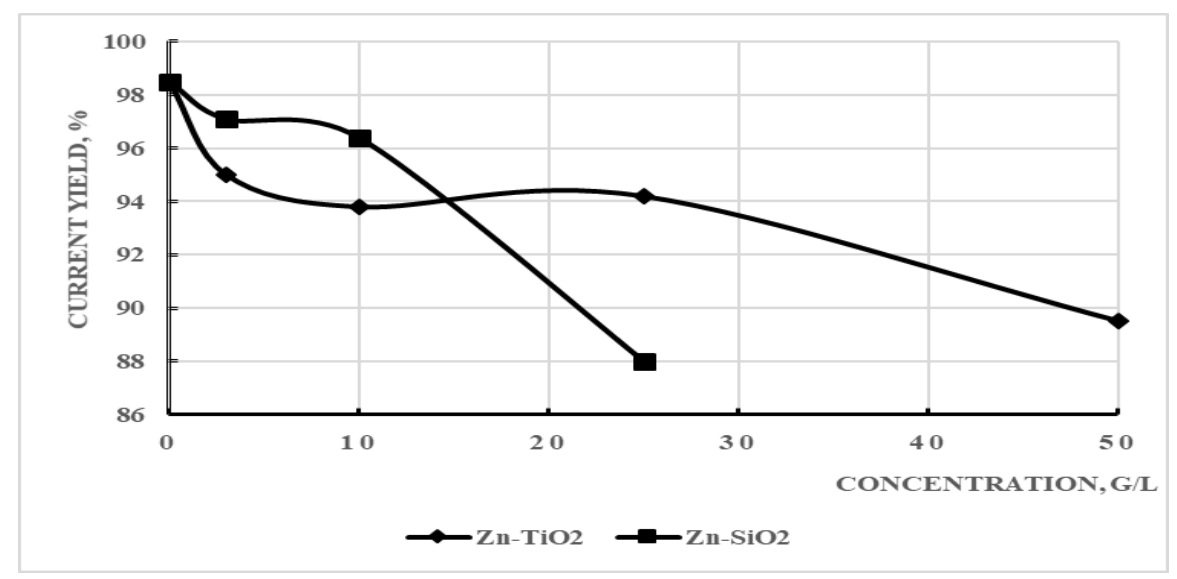

Fig. 1. Zinc current yield depending on the dispersed-phase concentration in electrolyte.

Particles of $\mathrm{TiO}_{2}$ reduce the true surface of coatings due to coprecipitation with the zinc matrix. The larger the value of including the $\mathrm{TiO}_{2}$ particles into the zinc matrix, the higher the zinc precipitation rate, which is observed in polarization curves (Fig. 2).

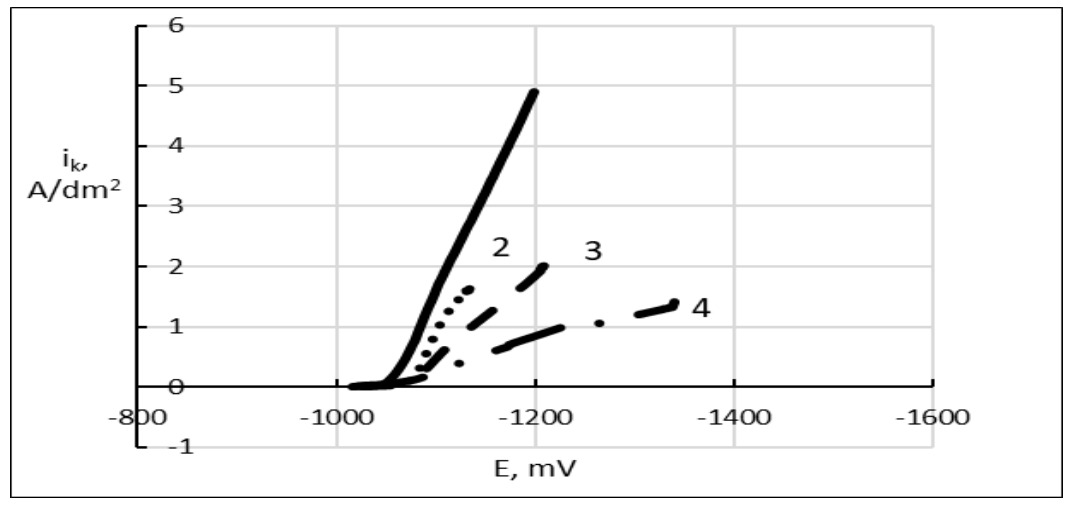

Fig. 2. Cathodic polarization curves in zincing electrolyte, depending on the $\mathrm{TiO}_{2}$ concentration: 1 $0 \mathrm{~g} / 1,2-50 \mathrm{~g} / \mathrm{l}, 3-10 \mathrm{~g} / \mathrm{l}$, and $4-3 \mathrm{~g} / \mathrm{l}$. Scanning velocity: $1 \mathrm{mV} / \mathrm{s}$. 


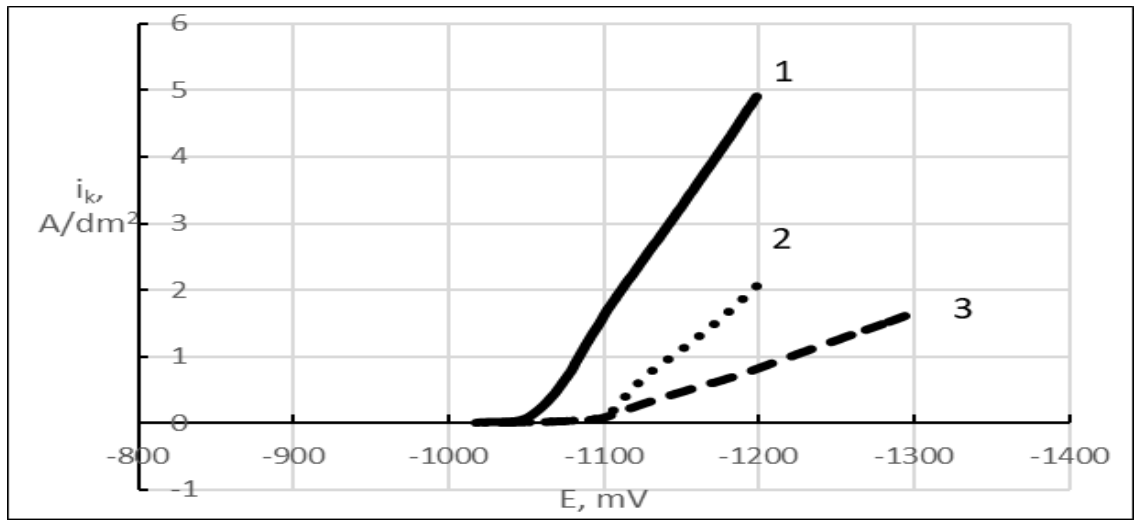

Fig. 3. Cathodic polarization curves in zincing electrolyte, depending on the $\mathrm{SiO}_{2}$ concentration: 1 $0 \mathrm{~g} / 1,2-10 \mathrm{~g} / 1$, and $3-25 \mathrm{~g} / 1$. Scanning velocity: $1 \mathrm{mV} / \mathrm{s}$.

Number of inclusions of the $\mathrm{TiO}_{2}$ particles $\left(\mathrm{a}_{\mathrm{m}}\right)$ into zinc matrix increases with increasing the concentration of the particles in suspended electrolyte. At the $\mathrm{TiO}_{2}$ concentration of $50 \mathrm{~g} / \mathrm{l}$, the number of inclusions into zinc matrix is $1.8 \%$. Coatings obtained at such concentration are of high quality and have no dendrites.

Identifying the number of inclusions of the $\mathrm{SiO}_{2}$ particles has shown that the values of $\mathrm{a}_{\mathrm{m}}$ of zinc coatings are negative. When increasing the concentration of the $\mathrm{SiO}_{2}$ particles in electrolyte from 3 to $25 \mathrm{~g} / \mathrm{l}$, the values of $\mathrm{a}_{\mathrm{m}}$ become more and more negative. Apparently, the particles are not included into the coatings, but they inhibit the electroreduction of zinc due to increasing the kinematic viscosity values of suspended electrolytes with the growing concentration of particles (Table 1 and Fig. 3).

To qualitatively and quantitatively analyze the phase composition of the coatings obtained, X-ray diffraction analysis was performed. It has shown that the control zinc coating and the $\mathrm{Zn}-\mathrm{TiO}_{2}$ and $\mathrm{Zn}-\mathrm{SiO}_{2}$ CECs have a hexagonal zinc structure on their surfaces, and their phase composition is as follows: $\mathrm{Zn}$ (P63/mmc(194), Hexagonal, ICDD PDF-2 01-078-9362). In XRD patterns with $\mathrm{Zn}-\mathrm{TiO}_{2}$ and $\mathrm{Zn}-\mathrm{SiO}_{2}$, the peak is shifted to the increasing the 2-theta angle, as compared to the control zinc coating, which is due to decreasing the interplanar spacing. This may indicate that, when introducing particles into the zincing electrolyte, the electro-crystallization of zinc changes. This, in turn, is proven by the microscopic investigations of how the dispersed phase of $\mathrm{TiO}_{2}$ and $\mathrm{SiO}_{2}$ affects the structure of the coating surfaces. Zinc is crystallized as hexagonal crystals. Zinc matrix crystal grain size is 8-10 $\mu \mathrm{m}$. Introducing the particles of $\mathrm{TiO}_{2}$ and $\mathrm{SiO}_{2}$ leads to reducing the grain size down to 6-8 $\mu \mathrm{m}$. Furthermore, in introducing dispersed phase, the structure of coatings alters markedly, and crystals do not have clear boundaries anymore, which may be caused by their destruction induced by particles.

To identify the elemental composition of the coatings studied, we analyzed them using scanning-electron microscopy and Auger electronic microscopy (Fig. 4 and 5). 

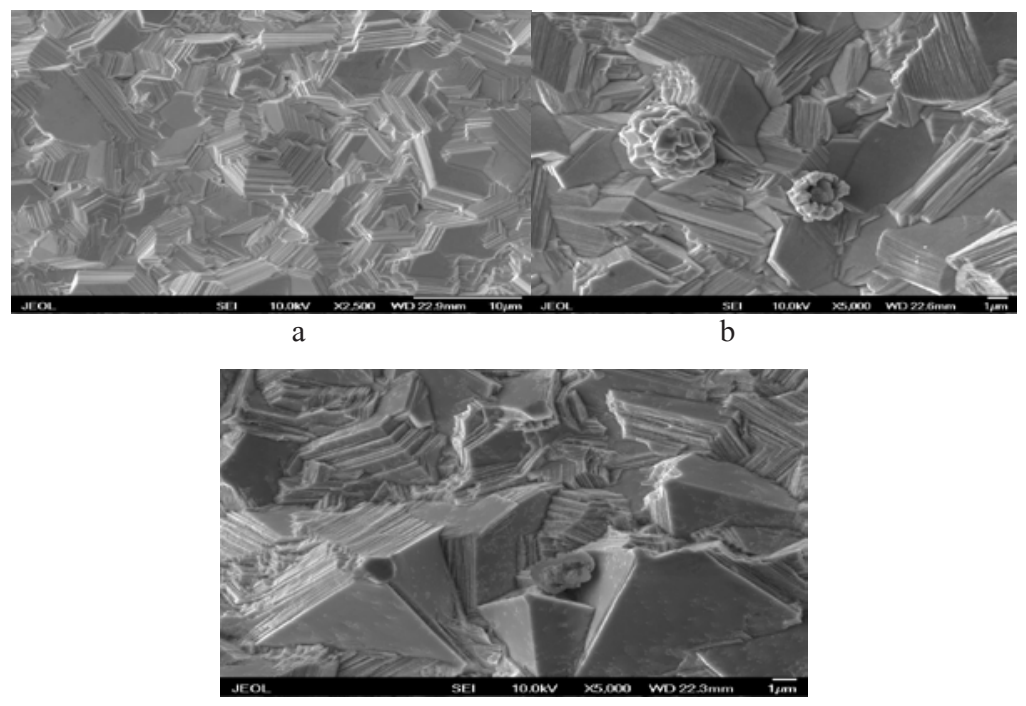

c

Fig. 4. Photomicrograph of zinc coating surfaces: a - Control coating; $b-\mathrm{Zn}-\mathrm{TiO}_{2}$; and c $-\mathrm{Zn}-\mathrm{SiO}_{2}$. $5,000 \mathrm{X}$ magnification.
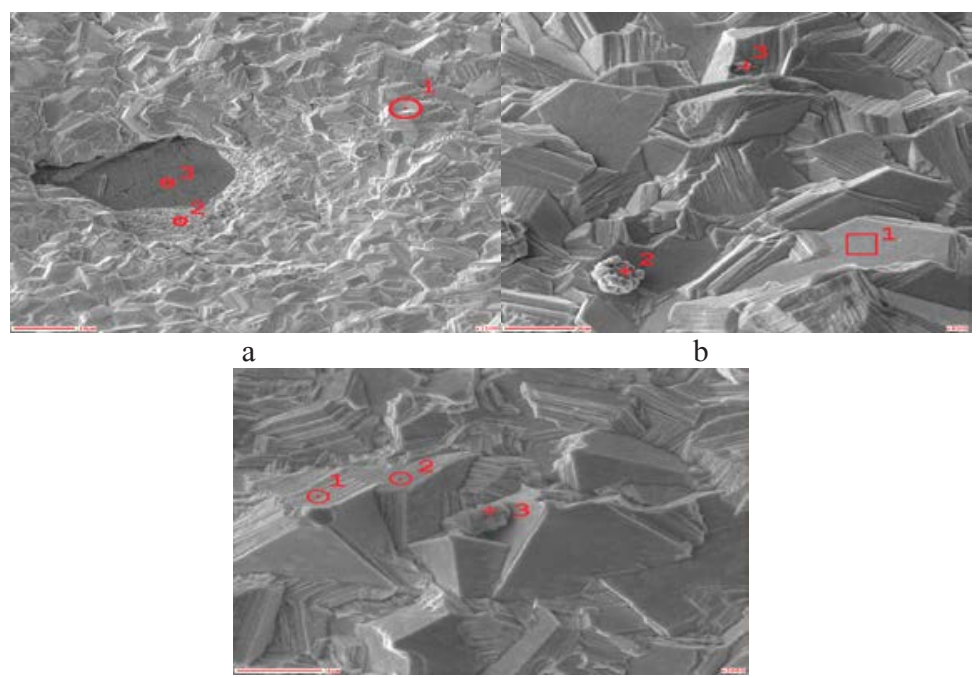

$\mathrm{c}$

Fig. 5. Selecting the review areas on zinc coating surfaces: $\mathrm{a}-$ Control coating; $\mathrm{b}-\mathrm{Zn}-\mathrm{TiO}_{2}$; and c $\mathrm{Zn}-\mathrm{SiO}_{2}$.

Fig. 4a shows the control zinc coating and, based on the findings from several areas on the coating surface, the surface morphology - developed (crystalline); there are coating imperfections, i.e., pitting (Fig.4a, area 3); surface structure is typical of electrodeposited zinc (lamellar-crystalline); and the elemental composition of the coating surface is as follows: $\mathrm{Zn}, \mathrm{O}, \mathrm{C}, \mathrm{S}$ and some traces of $\mathrm{Ca}$. Upon 1 minute of ion etching ( $3 \mathrm{kV}, \mathrm{Ar}+)$, pure $\mathrm{Zn}$ retains.

Fig. $4 \mathrm{~b}$ shows the composite electrochemical coating $\mathrm{Zn}-\mathrm{TiO}_{2}$ by the findings of analyzing several areas on the coating surface. Surface structure has the same composition as the control zinc coating. Surface morphology is as developed (crystalline) as that of the 
control coating, but it has spheric "capsules" sized $2 \div 6 \mu \mathrm{m}$; and the elemental composition of the coating surface is as follows: $\mathrm{Zn}, \mathrm{O}, \mathrm{C}$, and S. Upon 1 minute of ion etching $(3 \mathrm{kV}$, $\mathrm{Ar}+$ ), pure $\mathrm{Zn}$ retains. Elemental composition of the "capsule" wall (area 2) is $\mathrm{Zn}$ and $\mathrm{C}$ (upon ion etching, $3 \mathrm{kV}, \mathrm{Ar}+$ ); and the elemental composition of particles inside the "capsules" is $\mathrm{Ti}$ and $\mathrm{O}$ (intensity ratio of Auger peaks for $\mathrm{Ti}$ and $\mathrm{O}$ is relevant to the $\mathrm{TiO}_{2}$ stoichiometry).

Fig. 4c shows zinc coating with the $\mathrm{SiO}_{2}$ particles. Findings on several areas on the coating surface prove that the morphology and structure of the surface are typical of electrodeposited zinc and that no $\mathrm{SiO}_{2}$ particles are found on the coating surface.

Comparing the protective ability of $\mathrm{Zn}$ and $\mathrm{Zn}$-based CEC shows a sixfold decrease in corrosion index for CEC $\mathrm{Zn}-\mathrm{TiO}_{2}$. Apparently, the better corrosion resistance of the above $\mathrm{CEC}$ is determined by changes in the morphology of coatings. As to the $\mathrm{SiO}_{2}$ particles at the concentration of $10 \mathrm{~g} / \mathrm{l}$, they accelerate the corrosion rate by 1.5 times as compared to the control zinc coating, reducing respectively the corrosion resistance of the coating. This may be because the particles inhibit the electrodepositing of zinc, forming the $\mathrm{SiO}_{2}$ agglomerates, without incorporating into the zinc matrix.

\section{Conclusions}

1. It is found that dispersed-phase particles reduce the zinc current yield with increasing the concentration of the particles. With the $\mathrm{TiO}_{2}$ particles, the current yield falls from $98.4 \%$ down to $89.5 \%$ at the concentration of $50 \mathrm{~g} / 1$. $\mathrm{SiO}_{2}$ particles reduce the current yield from $98.4 \%$ down to $87.9 \%$ at $\mathrm{C}_{\mathrm{SiO} 2}=25 \mathrm{~g} / 1$.

2. It is also found that the $\mathrm{TiO}_{2}$ particles are included into the zinc coating, and the value of $\mathrm{a}_{\mathrm{m}}$ increases from $0.4 \%$ up to $1.8 \%$ with increasing the particles concentration from 10 up to $50 \mathrm{~g} / 1$.

3. As experiments show, the $\mathrm{SiO}_{2}$ particles are not included into the coating, but they change its morphology, which is confirmed by microscopic investigations.

4. It is found that zinc is crystallized on the obtained coatings as hexagonal crystals. Interplanar space decreases, which indicates changes in the zinc crystallization when introducing dispersed phase.

5. Using scanning and Auger microscopy, we have shown the elemental composition of a zinc coating with the particles of $\mathrm{TiO}_{2}$ and $\mathrm{SiO}_{2}$.

6. Introducing the $\mathrm{TiO}_{2}$ particles into the coating composition leads to enhancing their corrosion resistance. $\mathrm{SiO}_{2}$ particles reduce the corrosion resistance of coatings, since they do not get included into the coatings, but change the electro-crystallization of zinc.

Authors of this paper highly appreciate Aleksey Denisov, Senior Engineer at the Diversified Laboratory Nanoanalitika, Kazan, for his assistance in performing the Auger electronic microscopy of coatings.

\section{References}

1. Sayfullin, R.S. Neorganicheskiye kompositsionnyye materialy [Inorganic Composite Materials]. Moscow: Khimiya [Chemistry]. (1983). (In Russian).

2. Gorelov, S.M., Tsupak, T.E. Elektroosazhdeniye KEP na osnove nikelya s dioksidom titana [Electrodeposition of Nickel-Based CECs with Titanium Dioxide]. In: Galvanotekhnika i obrabotka poverkhnosti [Electroplating and Surface Treatment]. V.22 (1), pp.24-29 (2014). (In Russian).

3. Grigorshin, A.G., Makarshin, L.L. Issledovaniye effektivnosti raboty katalizatora $\mathrm{Zn} / \mathrm{TiO}_{2} \mathrm{v}$ mikrokanalnom reaktore $\mathrm{v}$ reaktsii parovoy konversii metana [Study on the 
Efficiency of the $\mathrm{Zn} / \mathrm{TiO}_{2}$ Catalyst Activity in a Microchannel Reactor within the Steam Methane Reformation Reaction]. In: Kinetika $i$ kataliz [Kinetics and Catalysis]. V.50 (1), pp 15-21 (2009). (In Russian).

4. J. Cao J., Wu, Ferroelectric and Dielectric Properties of Strontium Bismuth Niobate Vanadates, Materials Protection, v 33(4), pp.8-12 (2000).

5. Tseluykin, V.N. O strukture i svoystvakh kompositsionnykh elektrokhimicheskikh pokrytiy [On Structure and Properties of Composite Electrochemical Coatings]. Review: Physical Chemistry of Surface and Protection of Materials, v 52(2), pp 171-184 (2016). (In Russian).

6. Eiler, R. The Chemistry of Silica (Russian edition). Moscow: Mir. (1982)

7. Proskurkin, E.V. Tsinkovaniye [Zinc Plating]. Moscow: Metallurgiya [Metallurgy]. (1988). (In Russian). 